\title{
Divulgação Científica: Para quê? Para quem? - Pensando sobre a História, Filosofia e Natureza da Ciência em uma Revisão na Área de Educação Científica no Brasil
}

Scientific Dissemination: What for? For whom? - Thinking about History, Philosophy and Nature of Science in a Review of the Scientific Education in Brazil

\author{
${ }^{(10}$ Cristina Spolti Lorenzetti, ${ }^{(1)}$ Anabel Cardoso Raicik, ${ }^{(1)}$ Felipe Damasio
}

Palavras-chave Resumo $O$ presente trabalho apresenta uma revisão bibliográfica Divulgação sobre o tema divulgação científica em periódicos brasileiros de ensino

Científica; de ciências no último decênio. Buscou-se, nos trabalhos, apontamentos

Revisão e reflexões dos autores acerca de: (i) para quê fazer ou se apropriar Bibliográfica; da divulgação científica; (ii) para quem se destina essa divulgação; História e Filosofia (iii) aspectos da história e filosofia da ciência; (iv) reflexões acerca da Ciência; de Natureza da Ciência. Foram identificados, inicialmente, um total Natureza da de 99 artigos. Após um exame preliminar, com o desenvolvimento Ciência. de categorias específicas, 36 deles foram objeto de uma análise pormenorizada. Uma das implicações dessa pesquisa sinaliza a necessidade de mais trabalhos e reflexões sobre aspectos metafísicos relativos à divulgação científica (questões de para quê e para quem) no âmbito de sua utilização no ensino e, inclusive e principalmente, acerca de sua relação com aspectos de História, Filosofia e Natureza da Ciência. 
Keywords Abstract This work presents a literature review about scientific Scientific dissemination in Brazilian journals on Science Education in the last Dissemination; decade. In the articles, we looked for notes and reflections by the Literature Review; authors about: (i) why do or appropriate scientific dissemination; (ii) History and to whom this dissemination is addressed; (iii) aspects of the history Philosophy of and philosophy of science; (iv) Nature of Science in general. of the Science; initial query returned 99 articles. After a preliminary examination, Nature of Science. with the development of specific categories, 36 of them were subject to a detailed analysis. One of the implications of this research signals the need for more work and reflections on metaphysical aspects related to scientific dissemination (questions of why and for whom), in the context of its use in teaching and even and mainly about its relationship with aspects of History, Philosophy and Nature of Science.

\section{Introdução}

Quando se trata de escolarização, quase sempre a discussão se limita aos meios, não aos fins. Conforme coloca Postman (2002), nesse processo existem dois problemas a sanar: um chamado de engenharia de educação e a outro metafísico. A questão que trata da engenharia da educação é essencialmente técnica e a metafísica o do porquê ensinar. Segundo o autor, a primeira problemática trata das metodologias, equipamentos, materiais e propostas de sequências didáticas; preocupação em seu ponto de vista supervalorizada. Não é difícil perceber que ela ocupa grande parte da produção e das publicações da área da educação científica com o objetivo de orientar o professor a como proceder em um ambiente de ensino, de como e o que ensinar.

Apesar da questão de engenharia ser supervalorizada, a metafísica parece ainda mais relevante: Para que ensinar ciência? Qual o papel do professor da área de educação científica? Esses questionamentos parecem deixar desconfortáveis até mesmo profissionais de educação científica experientes. O pesquisador e professor que se limita, pura e simplesmente, a questão da engenharia da educação pode estar preocupado em 'transmitir conhecimento'; principalmente em qual a melhor maneira de fazer isso. Ao refletir acerca de questões metafísicas, o professor pode enxergar-se como tendo um papel muito além de ensinar equações e leis, a de formar pessoas que possam se colocar diante da sociedade atual - marcada por mudanças drásticas e rápidas - sem ser subjugadas por ela. Não tendo como preocupação ensinar uma ciência que, em princípio, transmite apenas 'verdades', produzida por pessoas especiais e que traz certezas por ser uma entidade isolada. O ponto que se coloca não é o de minimizar a relevância do 'como fazer', pelo contrário, é pensá-lo em concomitância com o porquê e com o que fazer. Em outras palavras, no âmbito da pesquisa em ensino de ciências, como enfatiza Moreira (2004), é preciso ter clareza que ela envolve a produção (e reflexão) de conhecimentos dentro de marcos teóricos educacional, epistemológico e metodológico, coerentes entre si. 
A divulgação científica, como um campo que vem sendo e se consolidando como profícuo para o próprio ensino de ciências, pode abarcar questões estruturais semelhantes. Em tempos sombrios de negacionismo como o que assola a todos em plena pandemia de Covid-19, além de fértil, a divulgação torna-se um caminho necessário e ainda mais relevante. Por isso, importa pensar: para quem se destina essa divulgação? Em relação a questões essencialmente técnicas, analogamente a engenharia da educação, existem até mesmo manuais que orientam a forma como o divulgador científico deve proceder. Um exemplo é o Pequeno Manual de Divulgação Científica (Vieira, 2006); o autor sugere, além de uma linguagem mais acessível, sem equações ou jargões, que quando se aborda um cientista ele seja apresentado e, também, os objetivos com sua pesquisa. Quando a abordagem for acerca de uma teoria, por exemplo, Vieira (2006) sugere a sua 'contextualização histórica', em adição ao uso de analogias e exemplos.

Outro caso de obras com uma preocupação puramente técnica na divulgação científica é o Guia de Divulgação Científica (Dickson et al., 2004). Esse material reúne um texto com "dicas nos campos da divulgação científica" e salienta que ele "seja útil para divulgadores e pessoas interessadas no tema" (p. 9). Exemplos dessas 'dicas' estão em alguns dos títulos dos capítulos: "Como aproximar os jovens da ciência?", "Como faço para editar um artigo de ciência?" e "Como escrevo relatos sintéticos sobre questões relacionadas à ciência para formuladores de políticas?".

Cabe ressaltar que manuais e guias, como os citados, devem ser vistos com cautela, pois eles podem ser úteis, parcialmente, ao iniciante em divulgação científica, mas demandam reflexões e vigilâncias de cunho epistemológico e historiográfico, por exemplo, devido à superficialidade com que tratam aspectos de e sobre a ciência, não apenas, mas principalmente quando pensa-se na divulgação científica em contexto escolar. De qualquer forma, esses materiais parecem indicar que, assim como ocorre na área da educação científica, questões análogas a engenharia da educação, isto é, mais técnicas pura e simplesmente, também são supervalorizadas nesse campo.

Carlos Vogt, linguista brasileiro, por exemplo, expõe o seu conceito de cultura científica, que engloba diferentes culturas através/para/da ciência, para entender como diferentes empreendimentos ligados a ela estão articulados e como afetam e são afetados pela sociedade (Vogt et al., 2008). A partir de uma espiral da cultural científica, interlocuções entre a divulgação científica presentes no ensino não formal, informal e formal tornam-se visíveis. O autor defende uma divulgação científica mais contextual, que aborde não apenas os produtos da ciência, mas também o fazer científico (Vogt, 2012).

Reconhece-se que dentro da cultura científica, há diversos personagens que falam de esobre ciência com diferentes objetivos. Esses sujeitos, sejam eles professores, cientistas, jornalistas, divulgadores, apresentam e são influenciados por visões epistemológicas; estando elas explícitas ou não. A divulgação científica busca uma exteriorização da ciência e, nesse sentido, prioritariamente, permitir que as pessoas leigas, sobretudo, possam entender, ainda que parcialmente, o mundo em que vivem (Silva, 2006). Mas 
como frisa Matthews (1995), uma discussão de ciência demanda uma reflexão filosófica dela. Uma vez que a divulgação científica tem sido utilizada comumente com finalidades didáticas, e, inclusive, produzidas e promovidas em e por espaços de ensino "ignorar esta influência [visões epistemológicas] na educação é um passo perigoso rumo a uma metodologia de ensino pueril, quando não perniciosa" (Arthury, 2010, p. 16). É certo que o papel da divulgação vem evoluindo ao longo tempo e, nesse processo, o reconhecimento de que há transformação da linguagem científica para familiaridade de um público geral e/ou mais amplo e diversificado, é um dos aspectos mais relevantes às problematizações relacionadas ao porquê e ao como divulgar a ciência em distintos espaços (Albagli, 1996; Marandino et. al., 2003).

As culturas científica e tecnológica são componentes da cultura contemporânea e, além disso, a cultura científica é legitimada para ser abordada na escola e compõe a educação científica, desta forma, os textos de divulgação da ciência têm legitimidade para circular nas salas de aula [e no contexto de ensino em geral] (...). No espaço, particularmente, das aulas de ciências, mas não só, os professores e estudantes trazem e discutem temas sobre a ciência. Com que olhar, porém, estes devem ler esses textos (livros, artigos, vídeos...)? (Gouvêa, 2015, p. 35).

Pode-se e deve-se ir além de, simplesmente, divulgar conceitualmente a ciência, dissertando não apenas de, mas também sobre ela. A História e Filosofia da Ciência (HFC) além de poder contribuir para uma melhor compreensão de conceitos científicos, pode viabilizar reflexões acerca de Natureza da Ciência (NdC) (Gil Peréz et al., 2001; Moura, 2014; Peduzzi, 2001; Peduzzi \& Raicik, 2020). Dessa forma, questões relacionadas a sociologia, filosofia e a história, assim como a cultura, economia, costumes e geografia dos locais onde o conhecimento científico é construído, podem ser incorporadas ao ensino e à divulgação, permitindo que respostas, vínculos e reflexões mais robustos sejam dados, inclusive, a questões da metafísica.

No entanto, segundo Damasio e Peduzzi (2015), nem toda a abordagem de HFC pode ajudar em reflexões que permitam entender o empreendimento científico sem ser subjugado a acreditar em certezas, verdades, entidade isolada e na dicotomia certoerrado. Essa perspectiva equivocada de ciência é reforçada tanto no ensino formal, ao elevar personagens pontuais da história da ciência como gênios isolados 'descobridores' de um vasto conhecimento, por exemplo, como pelos diferentes meios de divulgação científica ao reportarem notícias, por vezes sensacionalistas, de 'grandes descobertas' (Bueno, 2010). Por isto é importante saber que tipo de abordagem se faz, ou se sugere fazer, de acordo com perspectivas filosóficas contemporâneas. Isso implica que os próprios materiais de divulgação científica, especialmente quando usados em sala de aula ou produzidos para ela, requerem cuidados historiográficos, uma vez que podem reforçar concepções inadequadas ou limitadas sobre a ciência (Raicik et al., 2017). Mais uma vez, pode-se salientar a relevância de discussões concomitantes e complementares entre o como, o porquê e o para quê ensinar e divulgar a ciência. 
Em outras palavras, isso significa reconhecer que discussões relativas a HFC e $\mathrm{NdC}$ precisam ser incorporadas tanto no desenvolvimento de materiais e ações de divulgação científica - pois ainda que visem um público leigo (ou geral e mais amplo) e possuam uma linguagem acessível, eles apresentam em suas entrelinhas visões de ciência e do trabalho científico - quanto na utilização de materiais de divulgação científica no ensino de ciências, potencializando e promovendo discussões dessa natureza com a vigilância epistemológica necessária.

É inegável a proficuidade e sólidas relações entre a divulgação e o ensino de ciências e, inclusive, a divulgação científica para o ensino (Almeida, 2015; Bueno, 2010; Giordan \& Cunha, 2015; Gouvêa, 2015; Marandino et al., 2003; Nascimento, 2008; Rendeiro et al., 2017; Xavier \& Gonçalves, 2014) isto é, aquela divulgação voltada para o ensino formal, marcada pela apropriação de materiais e/ou ações de DC por docentes, no âmbito de pesquisa ou não, objetivando uma formação mais integral e crítica ao abordar temas complementares aos já tradicionais, como uma ciência mais contextual e humana, na qual sejam discutidos aspectos de sua natureza.

Apesar disso, é preciso que professores e pesquisadores do campo do ensino de ciências

estejam atentos para intervir positivamente nos processos de transferência de contextos tão diferentes como é o caso da mídia e da escola. Entender o gênero da divulgação científica e analisar criticamente as publicações da divulgação das Ciências antes de levá-las à sala de aula [ou a um contexto outro de ensino, seja formal ou informal] de forma a torná-las ferramentas didáticas é tarefa do professor [ou do professor-pesquisador], pois ele é o elemento fundamental do processo. (Cunha \& Giordan, 2015, p. 83).

Nesse sentido, e voltando-se à divulgação científica com finalidades didáticas diversas, o presente artigo objetiva identificar e analisar em artigos de periódicos brasileiros específicos de educação científica, no último decênio, quatro questões: (i) se há e quais são as preocupações manifestadas pelos pesquisadores da área de ensino que escrevem acerca de divulgação científica em relação a questão metafísica, ou seja, para quê fazer ou se apropriar da divulgação científica; (ii) se os autores refletem para quem se destina ações ou interlocuções com a divulgação científica; (iii) se utilizam ou discorrem acerca da História e Filosofia da Ciência e sob que perspectiva o fazem e; (iv) se abordam reflexões acerca de Natureza da Ciência. Por fim, procura fazer uma análise de como os resultados encontrados podem fazer refletir a pesquisa e produção de ações e materiais de divulgação científica no âmbito da educação científica, a partir da sua interlocução, sobretudo, com a HFC e a NdC. 


\section{Desenvolvendo um levantamento bibliográfico: aspectos metodológicos e principais resultados}

O levantamento das publicações para a análise foi desenvolvido nos sites de revistas brasileiras de educação científica com qualis $\mathrm{A}^{1} \mathrm{em}$ Ensino, no período do último decênio (2010-2020²): Ciência \& Educação (C\&E) (A1), Ensaio: pesquisa em educação em ciências (A1), Revista Brasileira em Ensino de Física (RBEF) (A1), Alexandria (A2), Amazônia (A2), Caderno Brasileiro de Ensino de Física (CBEF) (A2), Investigações em Ensino de Ciências (IENCI) (A2), Revista Brasileira de Ensino de Ciência e Tecnologia (RBECT) (A2) e Revista Brasileira De Pesquisa Em Educação Em Ciências (RBPEC) (A2). Também se optou por fazer a análise nos periódicos A Física na Escola (FnE) (B2) e Química Nova na Escola (QnE) (B1) pela relevância que apresentam no campo de pesquisa em ensino de Física e Química ${ }^{3}$ e também por serem revistas com ênfase no ensino pertencentes a Sociedade Brasileira de Física (SBF) e Sociedade Brasileira de Química (SBQ), respectivamente. Examinou-se, primeiramente, os títulos dos trabalhos, seus resumos e palavras-chave. Encontrou-se 99 trabalhos que apresentam os termos: divulgação científica, divulgação das ciências, divulgação da ciência, divulgação de ciências ou DC. A síntese quantitativa dos trabalhos encontrados inicialmente é apresentada na Figura 1.

Cabe ressaltar que se entende que o termo divulgação científica é polissêmico; aliás, pode-se encontrar variações de seu uso e mesmo em sua grafia. Bueno (2010), Silva (2006) e Rendeiro et al. (2017), por exemplo, enfatizam que termos como comunicação da ciência, disseminação da ciência, jornalismo científico, utilizados por vezes como sinônimos de divulgação científica, não carregam, na prática, os mesmos objetivos e/ou públicos. Como explicita Gouvêa (2015), "ao longo da história da difusão de conhecimentos científicos no Brasil, fomos adotando diferentes denominações quanto à prática social de difundir conhecimento" (p. 18), como a popularização da ciência, a socialização das ciências, a própria cultura científica. Não obstante, por questões de recorte e limite do presente levantamento, eles não foram utilizados como descritores.

\footnotetext{
$1 \mathrm{Na}$ avaliação mais recente disponível na página da entidade quando esta revisão foi realizada.

$2 \mathrm{O}$ ano de 2020 foi analisado em seu primeiro semestre, apenas.

3 O presente artigo faz parte de uma pesquisa mais ampla envolvendo, além de a divulgação científica e aspectos relativos à natureza da ciência, um resgate histórico da tabela periódica com interlocuções entre ensino de física e química, em particular.
} 
Figura 1. Síntese quantitativa dos artigos encontrados inicialmente; por ano e por revista

\begin{tabular}{|c|c|c|c|c|c|c|c|c|c|c|c|c|}
\hline \multirow[b]{2}{*}{ Ano } & \multirow[b]{2}{*}{$\begin{array}{r}N^{\circ} \text { de } \\
\text { artigos }\end{array}$} & \multicolumn{11}{|c|}{$\mathrm{N}^{\circ}$ de artigos por revista } \\
\hline & & Uू & 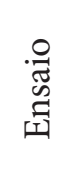 & 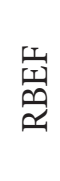 & 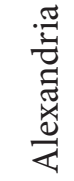 & 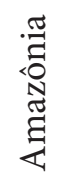 & $\begin{array}{l}\text { 荇 } \\
0 \\
0\end{array}$ & $\begin{array}{l}\circlearrowright \\
\text { Z } \\
\text { 出 }\end{array}$ & 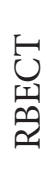 & $\begin{array}{l}0 \\
\text { yn } \\
2 \\
\text { حै }\end{array}$ & 秥 & 딤 \\
\hline 2010 & 11 & 2 & 2 & 0 & 0 & 0 & 1 & 2 & 1 & 2 & 1 & 0 \\
\hline 2011 & 4 & 2 & 0 & 0 & 1 & 0 & 0 & 0 & 0 & 0 & 0 & 1 \\
\hline 2012 & 10 & 1 & 1 & 1 & 2 & 0 & 2 & 0 & 1 & 1 & 0 & 1 \\
\hline 2013 & 6 & 2 & 1 & 0 & 1 & 0 & 1 & 0 & 1 & 0 & 0 & 0 \\
\hline 2014 & 8 & 2 & 0 & 1 & 2 & 0 & 1 & 0 & 1 & 1 & 0 & 0 \\
\hline 2015 & 16 & 2 & 0 & 1 & 3 & 0 & 2 & 2 & 0 & 2 & 0 & 4 \\
\hline 2016 & 6 & 1 & 0 & 0 & 2 & 0 & 1 & 0 & 0 & 1 & 0 & 1 \\
\hline 2017 & 14 & 4 & 1 & 2 & 0 & 1 & 1 & 1 & 1 & 2 & 1 & 0 \\
\hline 2018 & 10 & 2 & 0 & 2 & 0 & 1 & 1 & 0 & 1 & 3 & 0 & 0 \\
\hline 2019 & 8 & 1 & 1 & 0 & 2 & 1 & 0 & 0 & 1 & 0 & 2 & 0 \\
\hline 2020 & 6 & 0 & 1 & 0 & 0 & 0 & 1 & 1 & 1 & 0 & 0 & 2 \\
\hline Total & 99 & 19 & 7 & 7 & 13 & 3 & 11 & 6 & 8 & 12 & 4 & 9 \\
\hline
\end{tabular}

Fonte: autoria própria.

Após uma leitura minuciosa de cada um dos artigos selecionados previamente, procurou-se identificar quais trabalhos discutem explícita ou implicitamente: (i) para que produzir ou se apropriar da divulgação científica; (ii) o público-alvo da divulgação científica; (iii) a importância de incluir discussões de história e filosofia da ciência em materiais e atividades de divulgação científica e; (iv) questões acerca de natureza da ciência em concomitância com ações e materiais de divulgação científica. Desta forma, após a exclusão de trabalhos com a aplicação desses critérios, 36 deles passaram por uma análise ainda mais pormenorizada. A Figura 2 sintetiza esses trabalhos, enquanto a Figura 3 apresenta a sua quantidade por categorias ao longo dos dez anos analisados.

Figura 2. Trabalhos selecionados para análise pormenorizada, em ordem cronológica; por trabalho e critérios

\begin{tabular}{|l|l|l|l|l|}
\hline \multirow{2}{*}{} & \multicolumn{3}{|c|}{ Critérios } \\
\cline { 2 - 5 } & $\begin{array}{l}\text { Para que } \\
\text { produzir ou se } \\
\text { apropriar da } \\
\text { DC }\end{array}$ & $\begin{array}{l}\text { O público-alvo } \\
\text { da DC }\end{array}$ & $\begin{array}{l}\text { A importância } \\
\text { de incluir na } \\
\text { DC a HFC }\end{array}$ & $\begin{array}{l}\text { Questões } \\
\text { acerca de } \\
\text { NdC em } \\
\text { concomitância } \\
\text { com a DC }\end{array}$ \\
\hline $\begin{array}{l}\text { Colombo Junior e Silva } \\
(2010)\end{array}$ & $\checkmark$ & $\checkmark$ & & \\
\hline Carletti e Massarani (2011) & & $\checkmark$ & & $\checkmark$ \\
\hline $\begin{array}{l}\text { Kemper e Zimmermann } \\
(2011)\end{array}$ & $\checkmark$ & $\checkmark$ & & \\
\hline
\end{tabular}

Fonte: autoria própria. 
Figura 2. Trabalhos selecionados para análise pormenorizada, em ordem cronológica; por trabalho e critérios (continuação)

\begin{tabular}{|c|c|c|c|c|}
\hline \multirow[b]{2}{*}{ Artigo } & \multicolumn{4}{|c|}{ Critérios } \\
\hline & $\begin{array}{l}\text { Para que } \\
\text { produzir ou se } \\
\text { apropriar da } \\
\text { DC }\end{array}$ & $\begin{array}{l}\text { O público-alvo } \\
\text { da DC }\end{array}$ & $\begin{array}{l}\text { A importância } \\
\text { de incluir na } \\
\text { DC a HFC }\end{array}$ & $\begin{array}{l}\text { Questões } \\
\text { acerca de } \\
\text { NdC em } \\
\text { concomitância } \\
\text { com a DC }\end{array}$ \\
\hline Freire e Massarani (2012) & & $\checkmark$ & & \\
\hline Passoni et al. (2012) & $\checkmark$ & $\checkmark$ & & \\
\hline Rocha (2012) & $\checkmark$ & $\checkmark$ & & \\
\hline Urias e Assis (2012) & & & $\checkmark$ & \\
\hline Lobo e Martins (2013) & $\checkmark$ & $\checkmark$ & & $\checkmark$ \\
\hline Pauliv et al. (2013) & $\checkmark$ & $\checkmark$ & & $\checkmark$ \\
\hline Queiroz e Ferreira (2013) & $\checkmark$ & & & $\checkmark$ \\
\hline Góes e Oliveira (2014) & & & & $\checkmark$ \\
\hline Reznik et al. (2014) & $\checkmark$ & & & $\checkmark$ \\
\hline Sousa et al. (2014) & $\checkmark$ & & $\checkmark$ & $\checkmark$ \\
\hline Cardoso et al. (2015) & & $\checkmark$ & & $\checkmark$ \\
\hline Fraga e Rosa (2015) & $\checkmark$ & $\checkmark$ & & \\
\hline Oliveira e Carvalho (2015) & $\checkmark$ & & & \\
\hline Pena e Teixeira (2015) & & & $\checkmark$ & \\
\hline Roxael et al. (2015) & & $\checkmark$ & & $\checkmark$ \\
\hline Schmiedecke e Porto (2015) & $\checkmark$ & & $\checkmark$ & $\checkmark$ \\
\hline Watanabe e Kawamura (2015) & $\checkmark$ & $\checkmark$ & & $\checkmark$ \\
\hline Gomes et al. (2016) & $\checkmark$ & $\checkmark$ & $\checkmark$ & $\checkmark$ \\
\hline Caldas e Cristino (2017) & $\checkmark$ & $\checkmark$ & & \\
\hline Mota et al. (2017) & $\checkmark$ & $\checkmark$ & & $\checkmark$ \\
\hline Pereira e Valle (2017) & & $\checkmark$ & & \\
\hline Raicik et al. (2017) & $\checkmark$ & $\checkmark$ & $\checkmark$ & \\
\hline Watanabe e Kawamura (2017) & $\checkmark$ & & & $\checkmark$ \\
\hline Batistele et al. (2018) & $\checkmark$ & $\checkmark$ & & $\checkmark$ \\
\hline Mori e Curvelo (2018) & $\checkmark$ & $\checkmark$ & & \\
\hline Santos e Cunha (2018) & $\checkmark$ & & & \\
\hline Souza e Rocha (2018) & $\checkmark$ & & & $\checkmark$ \\
\hline Busko (2019) & $\checkmark$ & & & $\checkmark$ \\
\hline Costiche et al. (2019) & $\checkmark$ & $\checkmark$ & & \\
\hline Diniz e Rezende Junior (2019) & & $\checkmark$ & & $\checkmark$ \\
\hline Miceli e Rocha (2019) & $\checkmark$ & & & $\checkmark$ \\
\hline Almeida (2020) & $\checkmark$ & $\checkmark$ & & \\
\hline Watanabe et al. (2020) & $\checkmark$ & $\checkmark$ & & $\checkmark$ \\
\hline Total & 28 & 23 & 6 & 20 \\
\hline
\end{tabular}

Fonte: autoria própria. 
Figura 3. Número de trabalhos por categorias ao longo dos dez anos analisados

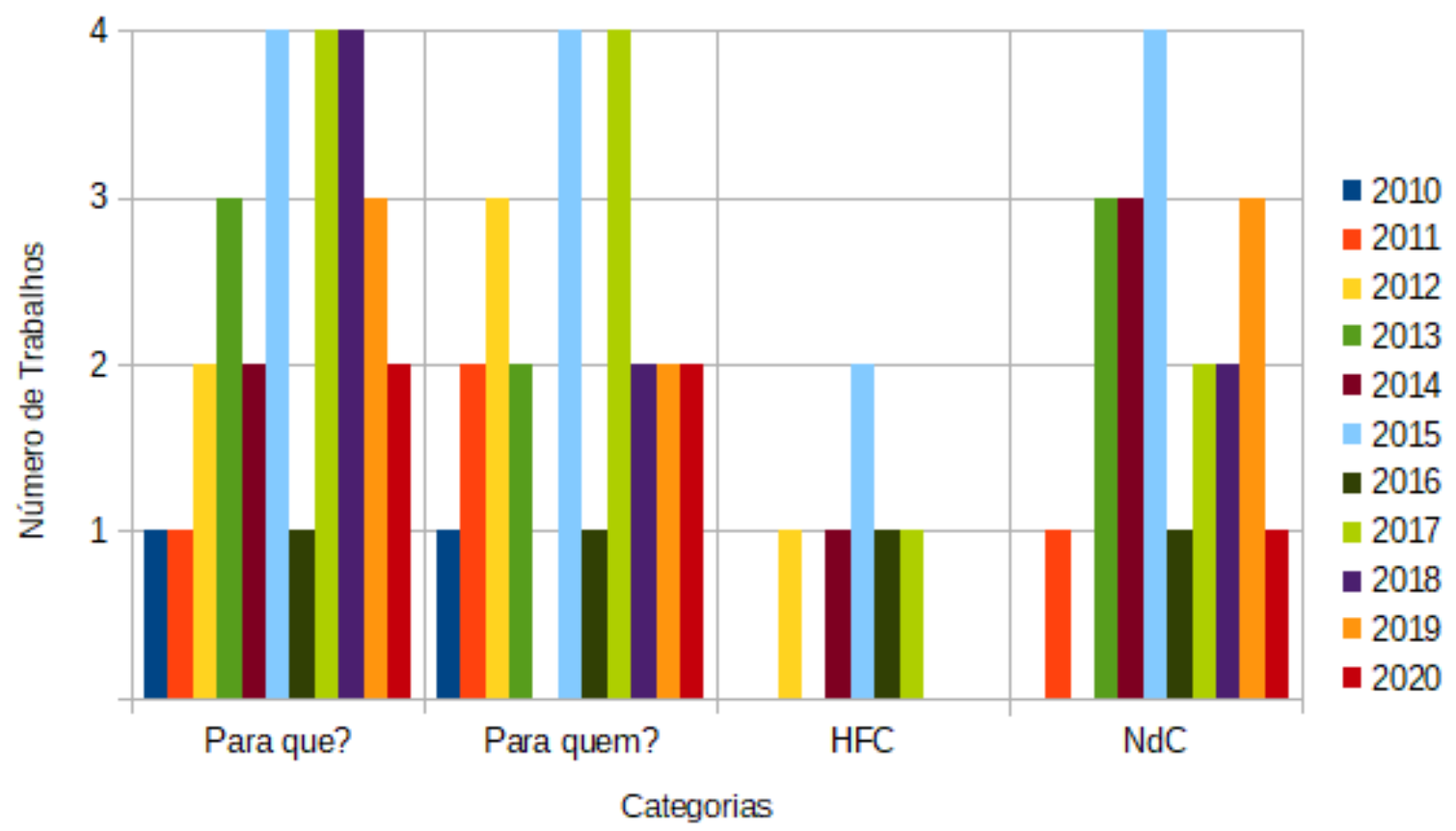

Fonte: autoria própria.

Além de uma caracterização geral dos trabalhos, conforme os quatro critérios acima estabelecidos, buscou-se analisar se os trabalhos trazem reflexões - e em que sentido o fazem - ao discutirem para que produzir ou se apropriar de materiais e ações de divulgação científica, se e o que sugerem ao discutirem para quem se destina essa divulgação, em que perspectiva se fundamentam ao estabelecerem uma relação com a HFC e que reflexões propõem ou promovem a partir da NdC.

Cabe ressaltar que apesar de terem sido classificados a partir do direcionamento dos quatro critérios supracitados, um mesmo artigo pode aparecer em mais de uma categoria, devido as sobreposições existentes entre elas. É comum que os trabalhos, sobretudo em suas considerações finais, apresentem reflexões e/ou desdobramentos que envolvam a divulgação científica nas distintas vertentes que conduziram este levantamento bibliográfico. Principalmente ao que se refere a questões de para que e para quem produzir ou se apropriar da divulgação científica a interlocução fica evidente; devido as particularidades em que essas discussões surgem, ligadas diretamente ao objetivo dos trabalhos em específico e a estudos de casos particulares. O mesmo ocorre, em alguns casos, com a $\mathrm{HFC}$ e a $\mathrm{NdC}$, principalmente porque a história da ciência propicia, de forma profícua, a exemplificação ou contra exemplificação de aspectos sobre a ciência. Nesse sentido, a seguir, discorre-se sobre os 36 trabalhos a partir de novas três classificações/agrupamentos: (i) os que discutem para que e para quem, mas não ponderam necessariamente acerca de aspectos de $\mathrm{HFC}$ e/ou NdC; (ii) aqueles que apresentam interlocuções com a HFC e/ou NdC e também com questões de para que e/ ou para quem; por fim (iii) aqueles que se limitam a discussões envolvendo $\mathrm{HFC}$ e/ $\mathrm{NdC}$, mas não discorrem explicitamente para que e/ou para quem. 


\section{Divulgação científica: Para quê e para quem?}

Encontrou-se 13 trabalhos que discutem, de alguma forma, para que e/ou para quem produzir ou se apropriar da divulgação científica; seja via produção ou análises de materiais, quer na promoção de eventos que popularizem e/ou aproximam a ciência tanto para um público leigo cientificamente, quanto para estudantes - mas que não estabelecem vínculos com a HFC e/ou NdC. Fraga e Rosa (2015) e Rocha (2012) argumentam que a divulgação científica permite uma aproximação entre o empreendimento científico e a sociedade; consequentemente, pode auxiliar na desconstrução de estereótipos acerca da ciência e na sua democratização. No primeiro caso, os autores analisam textos de divulgação científica publicados na revista Ciência Hoje das Crianças acerca de microbiologia, portanto as principais reflexões que estabelecem estão voltadas ao público infantil. Rocha (2012), por sua vez, ressalta a potencialidade que textos de divulgação científica podem apresentar ao serem inseridos no contexto escolar, dinamizando as aulas, apresentando atualização dos conteúdos de ciência, incentivando e aumentando o interesse dos alunos à prática de leitura desse gênero textual.

A importância de espaços não-formais de divulgação científica para que os estudantes da educação básica possam ter outras formas de construir conceitos relacionados a ciência, foi constatada em Oliveira e Carvalho (2015), Colombo Junior e Silva (2010) e Santos e Cunha (2018). Neste último artigo, a título de exemplo, os autores apresentaram uma revisão bibliográfica de trabalhos desenvolvidos a partir de visitações ao Bosque da Ciência - "um espaço dedicado à divulgação científica, educação e lazer, que abriga uma vegetação florestal, animais da fauna amazônica de vida livre e atrativos para a visitação turística" (Bosque da Ciência, 2020) - e evidenciam que a maior parte deles tratam do seu potencial educativo, mas como salientam, a falta de um referencial construtivista que guie a dinâmica do parque é, ainda, uma lacuna.

Ações de divulgação científica diretamente educativas, são encontradas em Passoni et al. (2012), Mori e Curvelo (2018), Caldas e Crispino (2017) e Costiche et al. (2019). Nesses casos, feiras de ciências, gincanas, oficinas, teatros, jogos educativos, materiais experimentais, jornal educativo e até palestras são promovidas e produzidas para aproximar a universidade e o ensino básico, oferecendo aos estudantes da graduação a oportunidade da vivência escolar, para que pesquisas feitas no meio acadêmico cheguem a esse contexto. Como frisam Caldas e Crispino (2017), palestras de divulgação promovidas para estudantes de nível básico podem influenciar, de maneira positiva, na escolha dos alunos por uma carreira científica.

Freire e Massarani (2012), Almeida (2020) e Carletti e Massarani (2011) preocupam-se, principalmente, nas particularidades que precisam estar presentes na divulgação científica para o público infantil. Estabelecendo reflexões explícitas com o ensino, Almeida (2020) analisa uma atividade desenvolvida com crianças do $4^{\circ}$ ano do ensino fundamental; como a atividade é voltada para alunos de idade entre 9 e 10 anos, as discussões que promovem restringem-se a este público. A autora identificou algumas limitações no uso do texto de divulgação científica que não foi desenvolvido 
especificamente para aquele contexto - apontando principalmente que o objetivo da construção do texto não era sua utilização em sala de aula. Apesar disso, constatou que a interação das crianças com o material pode ajudar no letramento, ampliando os horizontes de compreensão da linguagem científica. Carletti e Massarani (2011), igualmente com clara interlocução com o ensino-aprendizagem, realizaram uma pesquisa com crianças sobre as suas percepções sobre a Teoria da Evolução com o objetivo de obter dados para a criação de materiais de divulgação sobre esse assunto voltado àquele coletivo. Pereira e Valle (2017) traçaram um perfil dos visitantes do Centro de Pesquisa de História Natural e Arqueologia do Maranhão - um museu - e constataram que o seu público é composto majoritariamente por estudantes (de nível básico e superior), seguido de professores, profissionais liberais, funcionários públicos e aposentados. De acordo com a pesquisa desenvolvida, as visitas não seguem um padrão e variam de acordo com os visitantes. Todavia, concluíram que o próprio discurso do museu havia sido 'escolarizado'; apresentavam tipicamente um discurso pedagógico semelhante àquele presente no ensino formal.

É possível perceber que devido ao objetivo de cada trabalho, voltado diretamente a educação científica e tecnológica, em termos gerais, não há uma preocupação mais teórica e abrangente tanto acerca de objetivos relativos a própria divulgação científica e seu papel na sociedade, quanto de seus distintos públicos-alvo, e suas atividades e materiais. Apesar de os periódicos analisados serem específicos de educação científica, isso não diminui a necessidade de pesquisadores da área de ensino se apropriarem de referenciais da divulgação científica ao promoverem uma interlocução produtiva entre esses campos de conhecimento. Como apontam Lima e Giordan (2015), o docente que pretende utilizar materiais (ou promover ações e eventos) de divulgação científica necessita se apropriar "dessa ferramenta cultural". Não obstante, "esse processo de apropriação nem sempre ocorre; assim, existem casos de uso direto da DC em situações formais de ensino que, todavia, às vezes não produzem os resultados esperados" (p. 286).

Sobretudo pela divulgação científica estar relacionada, também e fortemente, à luz do que o presente levantamento já constatou, ao ensino-aprendizagem da ciência, faz-se necessário pensar cada vez mais em fundamentações teóricas, apontamentos de benefícios e implicações da própria divulgação enquanto campo de pesquisa, quando busca-se relações a partir de suas ações potencialmente didáticas no ensino. A divulgação científica, assim como a própria ciência, modificou-se ao longo dos séculos (Silva, 2007). Dessa forma, torna-se importante também o desenvolvimento de estudos sobre como são os comportamentos, as relações, as formas e perspectivas epistemológicas entre o públicos-alvo da divulgação científica e a ciência; tanto no seu desenvolvimento primário quanto no seu uso em outros contextos. Isso para que os materiais e os meios pelos quais a ciência é disseminada, não sejam anacrônicos e/ou estejam fora do alcance/ cultura desse público. A partir das reflexões acerca da cultura científica, na qual a DC está inclusa, estabelecidas por Vogt (2012), por exemplo, torna-se mais adequado falar em culturas das divulgações científicas; pois há diferentes parâmetros que influenciam 
e que são influenciados pela ciência e a sua divulgação. Sendo assim, a busca por um 'padrão' se mostra complexa e de certa forma inalcançável; é preciso analisar a divulgação científica de forma particular para diferentes objetivos e grupos, seja de forma teórica ou prática. E o conhecimento disso parece fundamental para que educadores se apropriem da divulgação em sua amplitude de ações e materiais.

Vogt (2012) ao evidenciar as relações entre ciência e sociedade frisa a existência de mais de uma cultura dentro da cultura científica. Isso porque os diferentes agentes (cientistas, professores, jornalistas e entre outros) que divulgam a ciência, possuem linguagens, objetivos e perspectivas sobre a ciência diferenciados. Dentro do artifício analógico criado pelo autor - a espiral da cultura científica - as diferenças e os vínculos entre essas divulgações tornam-se aparentes. Vogt endossa a importância crescente da divulgação científica para a sociedade; uma divulgação que não apenas apresenta os resultados da ciência, mas que a discute em seus aspectos culturais, sociais e epistemológicos (Vogt et al., 2008).

Nessa perspectiva, essa divulgação científica seria muito pertinente também para o ensino, já que poderia auxiliar em discussões diferentes daquelas geralmente trazidas pelo livro didático. Poder-se-ia pensar em uma divulgação como potencializadora de um ensino que visa a formação de cidadãos mais críticos, que conhecem não apenas a ciência, mas a construção de seu conhecimento.

Existem diferentes razões para que professores das áreas de ciências considerem a possibilidade de trabalhar com textos e/ou outros recursos de divulgação científica em situações escolares, entretanto nem toda a divulgação é adequada e é preciso admitir a necessidade da seleção do que vai ser utilizado. Critérios de diferentes ordens são necessários para adotá-la como recurso didático, dentre os quais se destacam a reflexão sobre o que se pretende com o ensino e as características dos recursos selecionados. (Almeida, 2015, p. 43).

Por certo, apesar de o ensino de ciências e a divulgação científica, enquanto campos de pesquisas, possuírem objetivos distintos, em situações específicas e concretas eles não precisam ser excludentes e dicotômicos; pelo contrário. A divulgação científica se mostra cada vez mais útil em ações didáticas; quer em espaços formais ou informais de ensino. Nesse sentido, mais uma vez, salienta-se a relevância de educadores se apropriarem, conhecerem e se embasarem em questões metafísicas oriundas da divulgação com seus referenciais próprios.

\section{Divulgação científica: interlocuções com HFC e/ou NdC e as questões de para que e para quem}

Identificou-se 20 trabalhos que articulam questões de $\mathrm{HFC}$ e/ou $\mathrm{NdC}$ com a divulgação científica e, inclusive, apresentam reflexões - em diferentes medidas - acerca de para que e/ou para quem produzir ou se apropriar dessa divulgação. Schmiedecke e Porto (2015) e Raicik et al. (2017), discutem aspectos relativos à HFC de forma teórica e exemplificativa. Os primeiros analisaram dois programas televisivos, 
em que utilizaram como parâmetros a linguagem, os episódios históricos, a forma de retratar a vida dos cientistas e de apresentar as suas 'descobertas'. Para fundamentar essas reflexões, selecionaram exemplos e discutiram como eles não eram adequados segundo a historiografia e a filosofia da ciência contemporâneas. Já os últimos contextualizam, em termos histórico e epistemológico, o experimentum crucis de Isaac Newton. Os autores investigaram a noção de experimento crucial presente, ou não, em uma amostra de livros de divulgação científica. Em síntese, a análise desenvolvida reforça a importância do professor como contextualizador, reflexivo e crítico, em relação aos materiais de divulgação científica, sobretudo quando levados para a sala de aula.

Roxael et al. (2015) discutem de forma teórica a NdC, bem como a exemplificam com os objetos de análises dos seus temas. Isto é, trazem uma abordagem explícita do que entendem por NdC. Cardoso et al. (2015) e Diniz et al. (2019) apresentam uma perspectiva mais voltada para o ensino, com análises de materiais de divulgação científica e sua potencialidade em gerar discussões de $\mathrm{NdC}$ em sala de aula. Gomes et al. (2016) implementaram uma proposta didática com alunos do ensino superior, solicitando que lessem um texto de DC e transcrevessem alguns trechos com base em parâmetros elencados inicialmente, como a forma e conteúdo dos textos e seu potencial para o ensino. Eles destacam que alguns alunos chegaram a transcrever, simplesmente, nomes e datas como sendo conteúdos de HFC; indicativo de uma história puramente linear e descontextualizada. Os autores também solicitaram que transcrevessem trechos relativos à NdC; tanto alunos dos primeiros quanto dos últimos anos da graduação tiveram dificuldades em cumprir a tarefa, relatando que não tinham como desenvolvêla, pois não sabiam nem mesmo o significado de $\mathrm{NdC}$.

A escassez de trabalhos que discutem a presença e utilização de $\mathrm{NdC}$ em análises ou produções de materiais de DC ou em associação a eles, pode ser encontrada em Batistele et al. (2018). Os autores salientam isso a partir de um levantamento de atividades didáticas que utilizam divulgação científica em sua construção. Apesar de a grande maioria das pesquisas apontar que os materiais eram adequados para realizar tais discussões em sala se aula, poucas se debruçaram a discutir isso teórica e fundamentadamente. Busko (2019) apresenta uma discussão epistemológica, baseada na incomensurabilidade de Thomas Kuhn, fundamentada nas atuais discussões sobre $\mathrm{NdC}$ e ainda apresenta exemplos sobre como pode ser visualizada a incomensurabilidade na divulgação científica realizada por grupos de pesquisa rivais.

Pauliv et al. (2013) acaba sendo um caso isolado, em termos de artigos científicos, mas que exemplifica uma concepção equivocada e limitada da ciência que continua presente no ideário de muitos estudantes e leigos. Por mais que não trate de forma explícita discussões de $\mathrm{NdC}$, aborda uma componente dela que está presente nas atuais discussões sobre a ciência: o método científico. Infeliz e lamentavelmente, os autores afirmam que "A interatividade com os estudantes durante as atividades desenvolvidas tem como base a concepção do método científico" (p. 230, grifo nosso), ou ainda que durante as atividades "é despertada a curiosidade no aluno, estimulando-o a usar $o$ 
método científico na solução de problemas" (p. 231, grifo nosso). Assim, a perspectiva que foi apresentada pelos autores difere das reflexões presentes no âmbito da filosofia contemporânea e do constante esforço de pesquisadores e professores em propiciar uma aprendizagem significativa sobre a ciência; que não pode mais aceitar a ideia de um em princípio único e infalível - método científico.

Ao agrupar os trabalhos nessa categoria, percebe-se que são poucos os que abordam a $\mathrm{NdC}$ em uma perspectiva mais fundamentada teoricamente, e ainda mais com perspectivas de HFC. Destaca-se que 6 artigos, devido aos seus objetivos, não visam discorrer teórica e aprofundadamente questões relativas a interlocução entre $\mathrm{NdC}$ e DC; limitam-se a enfatizar pinceladamente, em suas implicações ou considerações finais, por exemplo, a relevância de discussões relativas à natureza da ciência e, sobretudo, a importância do professor, enquanto mediador, ao levar textos de divulgação para a sala de aula, como Kemper e Zimmermann (2011); Queiroz e Ferreira (2013); Lobo e Martins (2013); Souza e Rocha (2018); Miceli e Rocha (2013). É importante salientar, no entanto, que isso não desmerece os trabalhos em si, que atingem seus objetivos propostos. Tão somente, sinaliza a relevância de mais trabalhos estabelecerem de forma clara, explícita e pormenorizada essa relação.

Constatou-se 6 artigos que abordaram a $\mathrm{NdC}$ a partir de diferentes lentes, como a da sociologia da ciência, mas não citam a terminologia Natureza da Ciência propriamente: Sousa et al. (2014) (que também trouxe traços de reflexões em HFC); Reznik et al. (2014); Mota et al. (2017); Watanabe e Kawamura (2015); Watanabe e Kawamura (2017); Watanabe et al. (2020). Mesmo não tratando NdC de forma direta, trabalhos como o de Kemper e Zimmermann (2011) abordam a importância da mediação do professor na ponderação de materiais de divulgação científica em sala aula, quanto as inadequações que podem apresentar; gerando debates com o objetivo de refleti-las. Lobo e Martins (2013) ponderam de forma semelhante, analisando o uso de textos de divulgação no ensino, ou seja, ressaltam a importância do professor para problematizar os materiais e realizar discussões.

A escassez de trabalhos que relacionam questões de para que e/ou para quem se destina o uso e a promoção de divulgação científica e a HFC, é notória. No período aqui considerado apenas 2 artigos trataram dessas questões de forma aprofundada: Schmiedecke e Porto (2015) e Raicik et al. (2017). É bastante curioso que trabalhos que visam estabelecer interlocuções entre a divulgação científica e o seu uso no ensino, não tratem de forma profícua e com profundidade, questões relativas à HFC junto ao seu público-alvo ou seus propósitos. A literatura voltada ao ensino de ciências, por certo, tem destacado a significativa relevância desse campo de estudos nas últimas décadas (Damasio \& Peduzzi, 2018; Forato et al., 2011; Moreira, 2017; Peduzzi, 2001). A sua interlocução com a área da divulgação científica, embora pouco explorada, parece promissora e relevante frente a uma visão cada vez mais crítica da ciência, que tanto se almeja e necessita. 
Em síntese, a análise evidencia a importância da mediação de docentes, quando da utilização de materiais de divulgação científica ou da promoção de ações dessa natureza em atividades didáticas, no que se refere a discussões relativas a $\mathrm{NdC}$ e da própria HFC. Ponderando sobre a espiral da cultura científica de Vogt (2012) nesse sentido, essa mediação dos docentes torna-se necessária pelas características encontradas na produção e no fazer divulgação científica, quando esta não está diretamente ligada ao ensino formal. Ambos podem possuir espaços, tempos, objetivos e personagens distintos na cultura científica.

Embora não esteja ligada necessariamente a área de ensino de ciências, levanta-se uma reflexão: quando os materiais de divulgação científica não trabalham explicitamente aspectos relativos à $\mathrm{NdC}$, por exemplo, e apresentam conteúdos não adequados em uma perspectiva epistemológica contemporânea, quem mediará as discussões e reflexões quando o público for a população em geral e não os alunos? Nesse sentido, embora possa extrapolar o objetivo aqui levantado, destaca-se a importância da adequação dos materiais de divulgação científica, já na sua produção, em termos históricos e epistemológicos, sobretudo. Há trabalhos que analisam esses materiais e suas inadequações depois de prontos, o que pode ser útil para professores que queiram incluir esses materiais e discussões em suas aulas. Entretanto, não se diminui a relevância da produção de divulgação científica com discussões sobre $\mathrm{NdC}$ para o público em geral ou quando ela é produzida já visando um público que, de certa forma, está voltado ao contexto de ensino (eventos e materiais dirigidos a estudantes em geral, a professores em formação inicial e continuada etc.).

\section{Divulgação científica: interlocuções com a HFC e/ou NdC}

Discussões relacionadas entre a divulgação científica e a HFC e/ou NdC, mas não necessariamente envolvidas com questões relativas ao para que e/ou para quem foram encontradas em 3 trabalhos. Urias e Assis (2012) analisaram dois livros de DC que tratam da vida de Albert Einstein. Os autores compararam o conteúdo dos livros, buscando semelhanças, diferenças e omissões na apresentação da vida do cientista. Com isso, a reflexão que fizeram está ligada com 'que história' é retratada nesses materiais. Entretanto, essas discussões foram feitas de modo restrito ao conteúdo do livro, sem apresentar de forma clara a visão epistemológica dos autores. Pena e Teixeira (2013) investigaram e sistematizaram parâmetros para avaliar materiais (didáticos, paradidáticos, divulgação científica, artigos ou ensaios) com foco na abordagem da HFC. Ao que se refere a aspectos que podem servir de critérios para analisar livros de física, especificamente de divulgação científica, os autores salientam: "clareza e precisão na linguagem; evitar a mistificação da ciência; considerar o contexto da época; análise crítica de fontes primárias; e estudos históricos elaborados por profissionais especializados". O trabalho de Góes e Oliveira (2014) por sua vez discutiu a evolução dos estudos sobre o genoma humano e a euforia dos anos de 1990 associada a 'solução de todos os problemas' celulares relacionados a 
genética humana. Ressaltaram como o mapeamento do genoma foi apenas a ponta do iceberg desses estudos e como ainda há muito trabalho a ser feito. Os autores não citaram a terminologia Natureza da Ciência, entretanto falaram das evoluções, expectativas e frustrações do empreendimento científico, algo que está intrinsecamente associado a ela.

Considerando o total de artigos selecionados, constata-se, mais uma vez, a escassez de trabalhos que relacionam a HFC com o uso de materiais de DC ou a promoção de ações dessa natureza, em alguma medida ou perspectiva. E quando o fazem, são poucos os que se propõem ou objetivam desenvolver reflexões mais profundas e bem fundamentadas tanto em relação a HFC quanto em termos da DC. Essa análise, juntamente ao resultado do agrupamento anterior, especificamente relativos aos vínculos com a HFC, aponta para a necessidade de se pensar "qual história?" está sendo apresentada em materiais e ações de DC e como mediar o seu uso em termos histórico-filosóficos. Além disso, mostra necessidade de mais trabalhos se preocuparem com isso; tanto quando de seu uso no ensino, quanto no que se refere ao seu acesso a um público mais amplo.

Nos últimos anos é recorrente a preocupação pelo desenvolvimento de materiais, didáticos ou não, que apresentem uma vigilância epistemológica quando do resgate histórico da ciência, para não incorrerem em uma visão linear e a-histórica desse empreendimento; uma inadequação já há muito bem conhecida (Peduzzi, 2001). O meio científico-informativo do cidadão adulto, que não frequenta mais a escola, via de regra, é a divulgação científica e o jornalismo científico. Isso evidencia, também, a necessidade desses materiais atentarem para discussões epistemológicas e históricas, quando de sua construção para esse público. O desenvolvimento de materiais de divulgação científica com cuidados historiográficos e epistemológicos pode contribuir para uma visão mais crítica da própria ciência; visão que na atualidade, em que ela vive sua descrença, tornase mais relevante e emergente. Narrativas inadequadas e centradas no senso comum podem se mostrar perigosas e enganosas, tendo a potencialidade de influenciar, tornar ingênua e acrítica a perspectiva de ciência de muitas pessoas.

Como não há, e quiçá é desejável, um consenso acerca de definições de Natureza da Ciência (Peduzzi \& Raicik, 2020), não era de se esperar consensos nas relações feitas entre a DC e a NdC, ainda que esta divulgação esteja ligada, de alguma forma, às ações e usos no ensino. Como discutido anteriormente, alguns trabalhos apenas comentam sobre a $\mathrm{NdC}$, outros trazem perspectivas dos autores e análises sobre determinado assunto e alguns abordaram referenciais mais específicos para o estudo que estavam desenvolvendo, como as reflexões entre o empreendimento científico e a sociologia da ciência. Aqueles trabalhos que apresentam uma discussão explícita e fundamentada sobre o assunto ainda são poucos, assemelhando-se muito ao pequeno número de artigos que estabeleceram vínculos com a HFC. Inclusive, frisa-se mais uma vez a sobreposição de trabalhos entre essas duas categorias. Isso pode ser um indicativo de que a HFC, realmente, pode promover profícuas discussões e exemplificações de aspectos relativos à NdC. Torna-se cada vez mais importante que a HFC seja contextualizada, vista em 
sua amplitude, como uma forma de construir conceitos e não apenas com um anexo ao ensino; assim pode-se favorecer a elaboração de visões mais críticas sobre a $\mathrm{NdC}$ e própria história da ciência (Callegario et al., 2015).

\section{Considerações finais e desdobramentos}

O presente levantamento indicou (embora não tenha pretensão de generalidade) que, majoritariamente, há uma preocupação ou vínculos estabelecidos, nos artigos selecionados, entre a divulgação científica e mais de um critério elencado (para que, para quem, HFC, NdC), ilustrados na Figura 1.

No que diz respeito as preocupações em relação a questão metafísica, isto é, para que fazer ou se apropriar da divulgação científica, percebeu-se uma clara relação com reflexões de para quem ela se destina. Esse vínculo é extremamente positivo, pois ações e materiais de divulgação científica podem ser pensados e promovidos para distintos públicos; quer uma população mais geral, quer um coletivo com vínculo explícito com o ensino (estudantes, professores em formação inicial e/ou continuada, pesquisadores). Dos 13 trabalhos que discutem, de alguma forma, para que e/ ou para quem produzir ou se apropriar de divulgação sem vínculos com a HFC e/ou NdC, 8 deles apresentaram essa relação (Almeida, 2020; Caldas \& Cristino, 2017; Colombo Junior \& Silva, 2010; Costiche et al., 2019; Fraga \& Rosa, 2015; Mori \& Curvelo, 2018; Rocha, 2012; Passoni et al., 2012). Enquanto 8 trabalhos evidenciaram interlocução entre a questão de para que e a HFC e/ou NdC (Busko, 2019; Miceli \& Rocha, 2019; Queiroz \& Ferreira, 2013; Reznik et al., 2014; Schmiedecke \& Porto, 2015; Sousa et al., 2014; Souza \& Rocha, 2018; Watanabe, \& Kawamura, 2017). Apenas 2 deles (Oliveira \& Carvalho, 2015; Santos \& Cunha, 2018) expõem de forma centralizada essa preocupação metafísica. Constatou-se que os autores, ao discorrerem sobre o resgate e uso da divulgação científica, apresentaram preocupações específicas em relação ao contexto educacional que estavam inseridos.

A exemplo da análise acima, os trabalhos que ostentaram discussões relacionadas ao público-alvo da divulgação científica abordaram outros assuntos em concomitância. Além daqueles 8 supracitados que vincularam reflexões sucintas em torno de para que e para quem produzir ou se apropriar dessa divulgação, 11 artigos apresentaram, em alguma medida, discussões de para quem produzir ou se apropriar de materiais e ações de divulgação científica com questões relativas à HFC e/ou NdC (Batistele et al., 2018; Cardoso et al., 2015; Diniz \& Rezende Junior, 2019; Gomes et al., 2016; Lobo \& Martins, 2013; Mota et al., 2017; Pauliv et al., 2013; Raicik et al., 2017; Roxael et al., 2015; Watanabe \& Kawamura, 2015; Watanabe et al., 2020). Não obstante, eles também fazem essas reflexões voltadas para o caso específico envolvido em seus estudos. Carletti e Massarani (2011), Freire e Massarani (2012) e Pereira e Valle (2017), podem ser destacados por apresentarem, de forma mais específica, e com grau de pormenoridade, ponderações acerca do para quem a DC é destinada enquanto área de conhecimento. Discussões muito pertinentes foram feitas em trabalhos que abordaram as questões sociais da ciência com o seu público, como em Watanabe e Kawamura (2017) e Watanabe et al. 
(2020). Nos trabalhos em que a divulgação científica é inserida diretamente no contexto da educação formal seu público-alvo e seus objetivos são detalhados para essa situação. O que pode explicar a ausência de discussões mais amplas no sentido metafísico da divulgação científica e de seu público, mas que não exime o pesquisador em educação ou docente de entendê-la em seu estado primeiro de construção. É essencial entender o objetivo e para quem tal material/ação foi desenvolvida para poder adaptá-la ao novo propósito.

No levantamento, algo que chamou a atenção foi a escassez de trabalhos que analisaram e/ou exemplificaram episódios históricos, epistemologicamente fundamentados, envolvendo a DC. Cita-se que 4 artigos aparecem de forma concomitante entre as categorias, são eles Raicik et al. (2017), Gomes et al. (2016), Schmiedecke e Porto (2011) e Sousa et al. (2014). Destes, apenas Raicik et al. (2017) e Schmiedecke e Porto (2011) desenvolveram discussões relativas a HFC, tratando de episódios históricos específicos e fundamentados filosoficamente. Pena e Teixeira (2011) e Urias e Assis (2012), utilizaram parâmetros mais operacionais para discutir a história da ciência, não adentrando especificamente em reflexões epistemológicas.

Ao que se refere especificamente aos vínculos com a $\mathrm{NdC}$, salienta-se que aqueles artigos que a citam, mas não a fundamentam, geralmente trazem uma observação nas considerações finais sobre a potencialidade de materiais de divulgação científica para a promoção de discussões sobre a ciência no ensino. Entretanto, eles carecem de comentários particulares sobre como, efetivamente, poderiam gerar tais discussões, a exemplo de Kemper e Zimmermann (2011); Queiroz e Ferreira (2013); Lobo e Martins (2013); Souza e Rocha (2018); Miceli e Rocha (2013). Alguns artigos, por sua vez, não explicitam o termo $\mathrm{NdC}$, mas abordam alguns de seus aspectos e acabam promovendo discussões mais profundas, como Sousa et al. (2014); Reznik et al. (2014); Mota et al. (2017); Watanabe e Kawamura (2015); Watanabe e Kawamura (2017); Watanabe et al. (2020).

A literatura vem apontando, todavia, a necessidade e a proficuidade de discussões explícitas sobre a ciência no ensino de ciências (Forato et al., 2011; Mathews, 1995; Moura, 2014; Peduzzi \& Raicik, 2020). Não são suficientes discussões implícitas acerca da NdC, como percebe-se em muitos materiais, inclusive no âmbito da DC, para uma aprendizagem significativa do tema; ou a sua operacionalização posterior. A título de exemplo, salienta-se a constatação de Gomes et al. (2016), de que alunos de um curso de licenciatura, tanto de fases iniciais quanto finais, quando solicitados a transcrever trechos de materiais de divulgação científica que pudessem ser considerados relativos à natureza da ciência, não sabiam nem o seu significado. Embora a interlocução entre os trabalhos que tratam da DC com a NdC tenha sido apresentada em número considerável de artigos nesse levantamento (conforme figura 1) apenas Schmiedecke e Porto (2011), Roxael et al. (2015), Busko (2019), Cardoso et al. (2015), Diniz et al. (2019), Batistele et al. (2018) apresentaram discussões explícitas sobre ela. 
O presente levantamento evidencia um número expressivo de trabalhos que discutem ou apresentam a apropriação da divulgação científica pelo ensino de ciências. Assim, torna-se possível, e quase inevitável, estabelecer uma interlocução entre as discussões epistemológicas realizadas nessas duas áreas. Apesar disso, percebe-se que quando os vínculos estão relacionados com a HFC e/ou a NdC, duas categorias-foco do presente artigo, há um longo caminho a ser percorrido. Callegario et al. (2015), por exemplo, publicaram uma revisão bibliográfica sobre a História da Ciência no ensino de Química, na qual ressaltam quão significativo é pensar, para além das metodologias de ensino, o porquê do que será construído com elas. Os autores destacam a importância da sua inserção na formação de professores, desfazendo-se aos poucos de uma cultura histórica linear que permeia o ensino de ciências comumente, não só na química, mas nas ciências da natureza em geral (física, química, biologia). Aliás, a falta de material didático adequado envolvendo aspectos histórico-filosóficos na educação básica contribui para que alunos cheguem ao ensino superior sem condições mínimas para realizar reflexões sobre esse assunto (Pena \& Teixeira, 2013). Com isso, materiais de divulgação científica que utilizam aspectos de $\mathrm{HFC}$ e/ou $\mathrm{NdC}$ em sua construção podem ser oportunos não apenas para o seu público-alvo, que teria acesso a uma ciência mais contextual e humana, mas também para a própria educação científica, na qual esses materiais poderiam ser utilizados como fontes profícuas de discussões sobre a ciência. Afinal, "quando realizamos ações de divulgação, nosso objetivo é que o cidadão contemporâneo fique imerso na cultura científica, seja aculturado? Ou temos como objetivo que ele olhe criticamente para a cultura científica?" (Gouvêa, 2015, p. 31). Entendendo, assim como o faz Vogt, que se visa problematizar essa cultura, e reconhecendo, no âmbito de sua inserção no ensino, que o espaço de ensino é microssocial, reflexões concomitantes a asserções relativas à $\mathrm{NdC}$ podem ser promissoras e fundamentais em análises ou produções de materiais e ações de DC.

Em síntese, os resultados aqui encontrados auxiliam nas reflexões acerca de como tem sido debatidas questões que envolvam a HFC e a NdC no âmbito do uso de materiais e ações de divulgação científica em principais periódicos nacionais de educação científica, para além das próprias questões essenciais para que e para quem ela se destina. Um dos apontamentos que este levantamento traz é a necessidade do desenvolvimento de atividades (materiais, oficinas, vídeos, eventos etc.) de DC que estejam cada vez mais fundamentadas histórica e epistemologicamente. Com efeito, mas sem pretensão de generalidade, pode-se inferir que materiais de DC não adequados - em termos de uma historiografia ou filosofia contemporâneas, por exemplo - contribuem para uma visão restrita e inadequada da própria ciência.

O levantamento de materiais que discutem a divulgação científica no último decênio em periódicos de educação científica se faz importante em razão da necessidade de compreender a produção intelectual e as relações que estão sendo feitas na área, a fim de se desenvolver trabalhos que sejam mais pertinentes e coerentes com as lacunas existentes na literatura. Cabe ressaltar que a pesquisa aqui concebida faz parte de um 
projeto mais amplo de investigação, reflexão e produção e análise de materiais de divulgação científica que estejam fundamentados histórica e epistemologicamente a partir da historiografia e filosofia da ciência contemporâneas e que possam ser utilizados como geradores de discussões sobre ciência na educação científica (Lorenzetti et al., 2020a; Lorenzetti et al., 2020b).

Assim, os apontamentos aqui manifestos evidenciam a necessidade da produção de pesquisas que envolvam discussões explícitas e exemplificadas entre a DC e aspectos de HFC e NdC e também da interlocução desses referenciais com a educação científica. Esses dados reiteram a importância de pensar a construção e análises de textos, vídeos, podcasts, publicações em mídias sociais, exposições e entre outras atividades de DC, que discutam não somente $a$ ciência, mas também sobre ela como forma de potencializar seu uso em contexto de ensino. Além disso, também se torna importante entender quais aspectos da divulgação científica sofrem modificação/adaptação ao serem inseridos nesse espaço.

Aqui, correndo o risco de ser repetitivo, reitera-se a importância de materiais fundamentados epistemologicamente, que não apresentem a ciência dogmática, perfeita e sobre-humana. Além disso, se faz importante a disposição de trabalhos aos educadores que reflitam e exemplifiquem inadequações em materiais de divulgação científica já existentes, a fim de facilitar a sua utilização em sala de aula. A introdução de um material inadequado, junto a uma discussão conduzida pelo professor a partir da historiografia e filosofia da ciência contemporâneas também são capazes de gerar debates e podem auxiliar na construção de conhecimento de uma ciência mais humana, aproximandose mais da compreensão do modus operandi do empreendimento científico, evitando idealizações.

Em Sobre a Natureza da Ciência: asserções comentadas para uma articulação com a História da Ciência, por exemplo, Peduzzi e Raicik (2020), ao apresentarem uma série se proposições comentadas acerca de aspectos relativos à Natureza da Ciência como uma abordagem profícua para sua discussão e reflexão no ensino, enfatizam, inclusive que

(...) as proposições e todo arcabouço reflexivo que carregam seus comentários e fundamentos podem subsidiar a análise epistemológica de filmes (...) , vídeos/ séries (...), hipermídias (...), documentos históricos, narrativas históricas (...) enfim, de qualquer produção, didática ou não, relacionada a divulgação da ciência e do trabalho científico, podendo levar a um posicionamento crítico, consciente, sobre as visões de ciência (explícitas ou nas entrelinhas) que essas obras trazem inevitavelmente consigo (p. 46).

Considerando os resultados encontrados e vislumbrando as carências expostas, este levantamento evidencia que o campo merece e permite aprofundamentos e a perspectiva de novos estudos. Entre uma das possibilidades que se mostra relevante, encontra-se a análise de livros de divulgação científica que tratam da história da ciência, à luz da natureza da ciência, por exemplo. Um episódio histórico que se mostra muito 
rico em detalhes - dentre tantos outros que poderiam ser citados - e que possui muitas nuances e personagens esquecidos é o da construção da Tabela Periódica. Atentando-se a isso e em virtude do exposto neste trabalho, o próximo passo do projeto desenvolvido pelos autores será a análise do livro "O sonho de Mendeleiev: a verdadeira história da química” (Strathern, 2002). Com isso, pretende-se trazer reflexões ao ensino de ciências a partir de discussões relativas à natureza da ciência que podem ser potencializadas com o resgate histórico desenvolvido na obra de divulgação.

\section{Referências}

Albagli, S. (1996). Divulgação científica: informação científica para a cidadania? Ciência da Informação, 25(3), 396-404. http://revista.ibict.br/ciinf/article/view/639

Almeida, S. A. (2020). O texto de divulgação científica em uma aula sobre fermentação nos anos iniciais do ensino fundamental. Revista Brasileira de Ensino de Ciência e Tecnologia, 13(1), 255-276. http://dx.doi.org/10.3895/rbect.v13n1.9177

Almeida, M. J. P. M. (2015). Divulgação científica no ensino escolar: Possibilidades e limites. In M. Giordan, \& M. B. da Cunha (Org.), Divulgação Científica na sala de aula: Perspectivas e Possibilidades. Editora Unijuí.

Arthury, L. H. M. (2010). A cosmologia moderna à luz dos elementos da epistemologia de Lakatos (Dissertação de Mestrado, Universidade Federal de Santa Catarina, Florianópolis, Santa Catarina). Repositório Institucional - UFSC. http://repositorio. ufsc.br/xmlui/handle/123456789/92475

Batistele, M. C., Diniz, N. P., \& Oliveira, J. R. S. (2018). O uso de textos de divulgação científica em atividades didáticas: uma revisão. Revista Brasileira de Ensino de Ciência e Tecnologia, 11(3), 182-210. http://dx.doi.org/10.3895/rbect.v11n3.6002

Bueno, W. C. (2010). Comunicação Científica e Divulgação Científica: aproximações e rupturas conceituais. Informação \& Informação, 15(esp), 1-12. http://dx.doi. org/10.5433/1981-8920.2010v15nespp1

Busko, P. S. (2019). A incomensurabilidade na ciência e suas implicações na divulgação científica a partir da epistemologia de Thomas Kuhn. Revista Brasileira de Ensino de Ciência e Tecnologia, 12(3), 241-257. http://dx.doi.org/10.3895/rbect.v12n3.8506

Caldas, J., \& Crispino, L. C. B. (2017). Divulgação científica na Amazônia: O Laboratório de Demonstrações da UFPA. Revista Brasileira de Ensino de Física, 39(2), e2309. https:// doi.org/10.1590/1806-9126-rbef-2016-0229

Callegario, L. J., Hygino, C. B., Alves, V. L. O., Luna, F. J., \& Linhares, M. P. A. (2015). História da Ciência no Ensino de Química: Uma Revisão. Revista Virtual de Química, 7(3), 977-991. http://dx.doi.org/10.5935/1984-6835.20150053 
Cardoso, D., Noronha, A., Watanabe, G., \& Gurgel, I. (2015). Texto jornalístico sobre ciência: uma análise do discurso sobre a natureza da ciência. Alexandria: Revista de Educação em Ciência e Tecnologia, 8(3), 229-251. https://doi.org/10.5007/19825153.2015v8n3p229

Carletti, C., \& Massarani, L. (2011). O que pensam crianças brasileiras sobre a teoria da evolução? Alexandria: Revista de Educação em Ciência e Tecnologia, 4(2), 205-223. https://periodicos.ufsc.br/index.php/alexandria/article/view/37688

Colombo Junior, P. D., \& Silva, C. C. (2010). Percepção da gravidade em uma intrigante visita à casa maluca do CDCC/USP. A Física na Escola, 11(1), 15-19. http://www1.fisica. org.br/fne/phocadownload/Vol11-Num1/a051.pdf

Costiche, S. W. S., Kemper, D. C., Gomes, A. K. S., Frare, A. L., Cezaro, D. E. R., Firbina, J., Baumgarten, L. L., Mendes, M. L., Almeida, W. D., Martins, V. A., Silva, A. P. R. da., Parisoto, M. F., \& Friedrich, F. C. (2019). Dramatização e experimentação como recursos didáticos para o ensino e divulgação das ciências naturais. A Física na Escola, 17(1), 61-67. http://www1.fisica.org.br/fne/phocadownload/Vol17-Num1/a12.pdf

Damasio, F., \& Peduzzi, L. O. Q. (2015). A coerência e complementaridade entre a epistemologia de Paul Feyerabend e a Teoria da Aprendizagem Significativa Crítica no ensino de história da ciência. Investigações em Ensino de Ciência, 20(3), 61-83. http:// dx.doi.org/10.22600/1518-8795.ienci2016v20n3p61

Damasio, F., \& Peduzzi, L. O. Q. (2018). Para que ensinar ciência no século XXI? - Reflexões a partir da Filosofia de Feyerabend e do ensino subversivo para uma Aprendizagem Significativa Crítica. Ensaio, 20, e2951. http://dx.doi.org/10.1590/198321172018200114

Dickson D., Keating B., \& Massarani, L. (Eds.) (2004). Guia de divulgação científica. SciDev.Net.

Diniz, N. P., \& Rezende Junior, M. (2019). Textos de divulgação científica da revista Ciência Hoje online: potencial para discussão de aspectos da natureza da ciência. Alexandria: Revista de Educação em Ciência e Tecnologia, 12(2), 165-194. https://doi. org/10.5007/1982-5153.2019v12n2p165

Forato, T. C. M., Pietrocola, M., \& Martins, R. A. (2011). Historiografia e Natureza da Ciência em sala de aula. Caderno Brasileiro de Ensino de Física, 28(1), 27-59. https://doi. org/10.5007/2175-7941.2011v28n1p27

Fraga, F. B. F. F., \& Rosa, R. T. D. (2015). Microbiologia na revista Ciência Hoje das Crianças: análise de textos de divulgação científica. Ciência \& Educação, 21(1), 199-218. https://doi.org/10.1590/1516-731320150010013

Freire, A., \& Massarani, L. (2012). A cobertura de ciência para crianças: um estudo de caso em dois jornais brasileiros. Alexandria: Revista de Educação em Ciência e Tecnologia, 5(3), 101-126. https://periodicos.ufsc.br/index.php/alexandria/article/view/37738 
Gil Pérez, D., Montoro, I. F., Alís, J. C., Cachapuz, A., \& Praia, J. (2001) Para uma imagem não deformada do trabalho científico. Ciência \& Educação, 7(2), 125-153. https://doi. org/10.1590/S1516-73132001000200001

Góes, A. C. S., \& Oliveira, B. V. X. (2014). Projeto Genoma Humano: um retrato da construção do conhecimento científico sob a ótica da revista Ciência Hoje. Ciência \& Educação, 20(3), 561-577. https://doi.org/10.1590/1516-73132014000300004

Gomes, V. B., Silva, R. R., \& Machado, P. F. L. (2016). Elaboração de textos de divulgação científica e sua avaliação por alunos de Licenciatura em Química. Química Nova na Escola, 38(4), 387-403. http://dx.doi.org/10.21577/0104-8899.20160052

Gouvêa, G. (2015). A Divulgação Científica, da técnica e cidadania e a sala de aula. In M. Giordan, \& M. B. da Cunha (Org.), Divulgação Científica na sala de aula: Perspectivas e Possibilidades. Editora Unijuí.

Kemper, A., \& Zimmermann, E. (2011). Textos populares de divulgação científica como ferramenta didático-pedagógica: o caso da evolução biológica. Revista Brasileira De Pesquisa Em Educação Em Ciências, 10(3), 25-50. https://periodicos.ufmg.br/index. $\mathrm{php} / \mathrm{rbpec} / \mathrm{article} / \mathrm{view} / 4086$

Lobo, M., \& Martins, I. (2013). Representações Sobre Alimentação e Ciência em um Texto de Divulgação Científica: implicações para a educação em ciências. Alexandria: Revista de Educação em Ciência e Tecnologia, 6(3), 3-26. https://periodicos.ufsc.br/ index.php/alexandria/article/view/38006

Lorenzetti, C. S., Damasio, F., \& Raicik, A. C. (2020a). O episódio histórico do centenário eclipse deSobral e suasimplicações para o ensino de física por meio da divulgação científica. Educar Mais, 4(2), 294-307. https://doi.org/10.15536/reducarmais.4.2020.294-307.1800

Lorenzetti, C. S., Damasio, F., \& Raicik, A. C. (2020b). O Ano Internacional da Tabela Periódica e um sucinto resgate de sua história: implicações para a Educação Científica por meio da Divulgação Científica. Experiências em Ensino de Ciências, 15(3), 188-203. https://fisica.ufmt.br/eenciojs/index.php/eenci/article/view/778/731

Marandino, M., Silveira, R. V. M. da., Chelini, M. J., Fernandes, A. B., Rachid, V., Martins, L. C., Lourenço, M. F., Fernandes, J. A., \& Florentino, H. A. (25-29 de novembro, 2003). A Educação Não Formal e a Divulgação Científica: o que pensa quem faz?. IV Encontro Nacional de Pesquisa em Educação em Ciências (ENPEC).

Matthews, M. R. (1995). História, filosofia e ensino de ciências: a tendência atual de reaproximação. Caderno Catarinense de Ensino de Física, 12(3), 164-214. https:// periodicos.ufsc.br/index.php/fisica/article/view/7084

Miceli, B. S., \& Rocha, M. B. (2019). Análise de textos de divulgação científica sobre genética inseridos em livros didáticos de biologia. Alexandria: Revista de Educação em Ciência e Tecnologia, 12(2), 121-138. https://doi.org/10.5007/1982-5153.2019v12n2p121 
Moreira, M. A. (2017). Grandes desafios para o ensino da Física na educação contemporânea. Revista do Professor de Física, 1(1), 1-13. https://doi.org/10.26512/rpf. v1i1.7074

Moreira, M. A. (2004). Pesquisa básica em educação em ciências: uma visão pessoal. Revista Chilena de Educación Científica, 3(1), 10-17.

Mori, R. C., \& da Silva Curvelo, A. A. (2018). A Experimentoteca do Centro de Divulgação Científica e Cultural (CDCC-USP) e o Ensino por Investigação: Compromissos Teóricos e Esforços Práticos. Revista Brasileira de Pesquisa em Educação em Ciências, 18(3), 795818. https://doi.org/10.28976/1984-2686rbpec2018183795

Mota, G. P. dos R., Gontijo, G. B., \& Oliveira, J. R. S. de. (2017). A Revista "Pesquisa FAPESP" como Recurso para Abordagem da Sociologia da Ciência. Revista Brasileira de Pesquisa em Educação em Ciências, 17(3), 953-983. https://periodicos.ufmg.br/index. $\mathrm{php} / \mathrm{rbpec} /$ article/view/4631

Moura, B. A. (2014). O que é a Natureza da Ciência e qual a sua relação com a História e Filosofia da Ciência? Revista Brasileira de História da Ciência, 7(1), 32-46. https://www. sbhc.org.br/arquivo/download?ID_ARQUIVO=1932

Nascimento, T. G. (2008). Definições de divulgação científica por jornalistas, cientistas e educadores em ciências. Ciência em Tela, 1(2), 1-8. http://www.cienciaemtela.nutes.ufrj. br/artigos/0208nascimento.pdf

Oliveira, L. M., \& Carvalho, D. F. (2015). O método da lembrança estimulada como uma ferramenta de investigação sobre a visita escolar no museu de biodiversidade do cerrado. Investigações em Ensino de Ciências, 20(3), 151-163. http://dx.doi.org/10.22600/15188795.ienci2016v20n3p151

Passoni, L. C., Vega, M. R. G., Giacomini, R., Barreto, A. M. P., Soares, J. S. C., Crespo, L. C., \& Ney, M. R. G. (2012). Relatos de Experiências do Programa Institucional de Bolsa de Iniciação à Docência no Curso de Licenciatura em Química da Universidade Estadual do Norte Fluminense. Química Nova na Escola, 34(4), 201-209. http://qnesc. sbq.org.br/online/qnesc34_4/06-PIBID-66-12.pdf

Pauliv, V. E., Carvalho, L. C., Felippe, C., Bobato, R., \& Sedor, F. A. (2013). Programa "ciência vai à escola" - museu de ciências naturais da UFPR: construindo uma visão de ciência na educação básica. Revista Brasileira de Ensino de Ciência e Tecnologia, 6(2), 228-238. http://dx.doi.org/10.3895/S1982-873X2013000200015

Peduzzi, L. O. Q. (2001). Sobre a utilização didática da História da Ciência. In M. Pietrocola(Org.), Ensino de física: conteúdo, metodologia e epistemologia numa concepção integradora. Editora da UFSC.

Peduzzi, L. O. Q., \& Raicik, A. C. (2020). Sobre a Natureza da Ciência: asserções comentadas para uma articulação com a História da Ciência. Investigações em Ensino de Ciências, 25(2), 19-55. http://dx.doi.org/10.22600/1518-8795.ienci2020v25n2p19 
Pena, F. L. A., \& Teixeira, E. S. (2013). Parâmetros para avaliar a produção literária em História e Filosofia da Ciência voltada para o ensino e divulgação das ideias da Física. Caderno Brasileiro de Ensino de Física, 30(3), 471-491. https://doi.org/10.5007/21757941.2013v30n3p471

Pereira, B. O., \& Valle, M. G. (2017). O discurso museológico e suas tipologias em um museu de história natural. Ciência \& Educação, 23(4), 835-849. https://doi. org/10.1590/1516-731320170040004

Postman, N. (2002). O fim da educação - redefinido o valor da escola. Graphia.

Queiroz, S. L., \& Ferreira, L. N. de A. (2013). Traços de cientificidade, didaticidade e laicidade em artigos da revista 'Ciência Hoje' relacionados à química. Ciência \& Educação, 19(4), 947-969. https://doi.org/10.1590/S1516-73132013000400011

Raicik, A. C., Peduzzi, L. O. Q., \& Angotti, J. A. P. (2017). Uma análise da ilustração do experimentum crucis em materiais de Divulgação Científica. Física na Escola, 15(2), 24-30. http://www1.fisica.org.br/fne/phocadownload/Vol15-Num2/a05.pdf

Rendeiro, M. F. B., Araújo, C. P., \& Gonçalves, C. B. (2017). Divulgação Científica para o Ensino de Ciências. Revista Amazônica de Ensino de Ciências, 10(22), 141-156. http:// periodicos.uea.edu.br/index.php/arete/article/view/637

Reznik, G., Massarani, L., Ramalho, M., \& Amorim, L. (2014). Ciência na Televisão Pública: uma análise do telejornal Repórter Brasil. Alexandria: Revista de Educação em Ciência e Tecnologia, 7(1), 157-178. https://periodicos.ufsc.br/index.php/alexandria/ article/view/38182

Rocha, M. B. (2012). O potencial didático dos textos de divulgação científica segundo professores de ciências. Revista Brasileira de Ensino de Ciência e Tecnologia, 5(2), 47-68. http://dx.doi.org/10.3895/S1982-873X2012000200005

Roxael, F. R., Diniz, N. P., \& Oliveira, J. R. S. de (2015). O trabalho do cientista nos cartuns Sidney Harris: um estudo sob a perspectiva da sociologia da ciência. Química Nova na Escola, 37(esp. 1), 68-81. http://dx.doi.org/10.5935/0104-8899.20150020

Santos, S. C. S., \& Cunha, M. (2018). A pesquisa em espaços de educação não formal em ciências na Região Norte: o caso do Bosque da Ciência. Amazônia: Revista de Educação em Ciências e Matemáticas, 14(32), 160-173. http://dx.doi.org/10.18542/amazrecm. v14i32.5801

Schmiedecke, W. G., \& Porto, P. A. (2015). A história da ciência e a divulgação científica na TV: subsídios teóricos para uma abordagem crítica dessa aproximação no ensino de ciências. Revista Brasileira de Pesquisa em Educação em Ciências, 15(3), 627-643. https://periodicos.ufmg.br/index.php/rbpec/article/view/4332

Silva, H. C. (2006). O que é Divulgação Científica? Ciência \& Ensino, 1(1), 53-59. 
Sousa, A. C. de, Muxfeldt, A. K., Justina, L. A. D., \& Meglhioratti, F. A. (2014). A presença do tema Eugenia em uma revista de Divulgação Científica no período de 1990 a 2009. Revista Brasileira de Pesquisa em Educação em Ciências, 14(1), 31-53. https://periodicos. ufmg.br/index.php/rbpec/article/view/4281

Souza, P. H. R., \& Rocha, M. B. (2018). O caráter híbrido dos textos de divulgação científica inseridos em livros didáticos. Ciência \& Educação, 24(4), 1043-1063. http:// dx.doi.org/10.1590/1516-731320180040015

Urias, G., \& Assis, A. (2012). Análise de biografias de Einstein em dois livros de divulgação científica. Caderno Brasileiro de Ensino de Física, 29(2), 207-228. https://doi. org/10.5007/2175-7941.2012v29n2p207

Vieira, C. L. (2006). Pequeno manual de divulgação científica: dicas para cientistas e divulgadores da Ciência. Instituto Ciência Hoje.

Vogt, C. (2012). The spiral of scientific culture and cultural well-being: Brazil and Ibero-America. Public Understanding of Science, 21(1), 4-16. https://doi. org/10.1177\%2F0963662511420410

Vogt, C., Cerqueira, N., \& Kanashiro, M. (2008). Divulgação e cultura científica. ComCiência, (100). http://comciencia.scielo.br/scielo.php?script=sci_ arttext\&pid=S1519-76542008000300001\&lng=en\&nrm=iso

Watanabe, G., Munhoz, M. G., \& Kawamura, M. R. (2020). Contribuições da sociologia para o estudo da divulgação científica na interface campo científico e espaço escolar: um olhar a partir do conceito de fronteira. Revista Ensaio, 22, e105811. http://dx.doi. org/10.1590/1983-21172019210122

Watanabe, G., \& Kawamura, M. R. (2017). A divulgação científica e os físicos de partículas: a construção social de sentidos e objetivos. Ciência e Educação, 23(2), 303320. http://dx.doi.org/10.1590/1516-731320170020002

Watanabe, G., \& Kawamura, M. (2015). Um sentido social para a divulgação científica: perspectivas educacionais em visitas a laboratórios científicos. Alexandria: Revista de Educação em Ciência e Tecnologia, 8(1), 209-235. https://doi.org/10.5007/19825153.2015v8n1p209

Xavier, J. L. A., \& Gonçalves, C. B. (2014). A relação entre a divulgação científica e a escola. Revista Amazônica de Ensino de Ciências, 7(14), 182-189. http://periodicos.uea. edu.br/index.php/arete/article/view/135/133 
Cristina Spolti Lorenzetti

Instituto Federal de Santa Catarina Araranguá, Santa Catarina, Brasil cspolti55@gmail.com

Anabel Cardoso Raicik

Universidade Federal de Santa Catarina Florianópolis, Santa Catarina, Brasil anabelraicik@gmail.com

Felipe Damasio

Instituto Federal de Santa Catarina Araranguá, Santa Catarina, Brasil felipedamasioifsc@gmail.com

Editora Responsável

Stefannie Ibraim

Manifestação de Atenção às Boas Práticas Científicas e de Isenção de Interesse

Os autores declaram ter cuidado de aspectos éticos ao longo do desenvolvimento da pesquisa e não ter qualquer interesse concorrente ou relações pessoais que possam ter influenciado o trabalho relatado no texto. 